\title{
Further Investigation on the Regulation of B2C E-commerce Industry Structure in China -- Analysis Based on the Theory of Contestable Markets
}

\author{
Minhe Zhang \\ School of Economics, Huazhong University of Science and Technology, Wuhan, Hubei Province, China \\ efocus@189.cn
}

Keywords: Theory of Contestable Markets, network center, e-commerce industry, government regulation.

\begin{abstract}
In November, 2012, the author published an article titled Research on Regulating the Industrial Structure of Online Shopping Platforms in China in the journal of Contemporary Economics. In this article, a new idea on government regulation is proposed: the government can "establish an interconnected Internet center which is similar to UnionPay; a variety of payment platforms can be connected with this center. The Internet center provides credit guarantee and fund security services for both parties of the transaction." Coincidentally, in March 31, 2017, the Internet center "NetsUnion" started its trial operation. 7 units under the guidance of People's Bank of China holds 37\% shares; 29 third party payment institutions hold 63\% shares. They jointly invested 2 billion yuan to build the network platform. In this paper, the author employs the Theory of Contestable Markets again to analyze that after the establishment of network center, how can the government further help real economy enterprises to reduce the sunk cost of establishing electronic commerce platforms, how to make the monopolized e-commerce industry to become a competitive industry, and how to help more e-commerce enterprises to take shape and develop healthily. For the monopolistic e-commerce platforms, more effective regulations from the government are needed.
\end{abstract}

\section{Introduction}

In recent years, more and more enterprises are integrated into the e-commerce system through third-party e-commerce platform or self-built platform. Products and services which have integrated into the model of Internet + Sales develop rapidly. In the third quarter of 2017, the top five companies hold 92.6\% shares of China's B2C network retail market (includes open and self-running platforms; excludes brand e-commerce platforms). Among them, Tmall accounts for 59\%; Jingdong accounts for 26.9\%; Vipshop accounts for 3.2\%; Suning accounts for 2.8\%; Gome online accounts for 1.3\%. Although the industry is highly concentrated, the competition is still fierce. In November 20, 2017, Alibaba invested 22.4 billion Hongkong dollars to buy the stakes of Sun Art Retail Group; the customers of Feiniu were transferred to Tmall. The market shares of Tmall further increase. From these data it can be seen, natural monopoly exists in the B2C industry of China. But in recent years, the government actively supports the e-commerce industry through policies; the regulation of e-commerce industry becomes a dilemma. The author believes, the Contestable Markets Theory proposed at the beginning of 80s can still provide theoretical basis for the government when making regulation policies about the e-commerce industry.

\section{Basic Content of the Theory of Contestable Markets}

The theory of contestable markets (Dong-shui Su, 2001) is also known as the contestability theory. It was proposed by American economists Baumol, Panzar and Willing in the 1980s. The theory of contestable markets holds that, based on market competition, monopoly enterprises do not behave according to expected changes and speculation about the enterprise, but behave according to potential competition pressures which can be analyzed more easily. The theory is suitable for economies of scale and the natural monopoly oligopoly market. It does not object state intervention, but rediscover 
the roles of market and government.

The contestable markets refer to these markets, in which potential competition pressure can play the same role as real competition; potential competition pressure can threat and restraint monopolistic enterprises. These markets force monopoly enterprises to improve their efficiency. A fully contestable market is the extreme of contestable market. It refers to a market which enterprises can enter and exit with absolute freedom; no sunk costs should be burdened. The absolute freedom means, compared with existing companies, the new entrant has no technical or production disadvantages. That is to say, the condition of complete competition is no cost discrimination to the entrant.

Sunk cost refers to the part of cost which the enterprise cannot take back when it exits from the market. Sunk cost includes specialized equipments, invested time and manpower, research and development cost, advertising and intangible assets. The amount of sunk cost directly determines the difficulty of exit, and affects the decision of a company to enter the market. Therefore, the competition degree of a market depends on the sunk cost of an enterprise when it exit the market.

In fully contestable markets, there is no entry or exit barrier; potential entrants can adopt the strategy of "hit and run". If the industry has a relatively high excess profit, potential entrants will quickly enter the market and then exist before incumbent firms' reaction. It is the existence of potential competition, rather than real competition, which restrains the market behavior of companies effectively. The whole industry will be in a state of equilibrium with effective pricing but without excess profit.

There are strict assumptions in the theory of contestable markets. First, the entry of potential enterprises is completely free; there are no restrictions. The newcomer can quickly replace the original enterprises. Second, potential enterprises can enter the market rapidly. Third, enterprises can exit the market completely free; the sunk cost is zero. The strategy of "hit and run" is effective only when there is no adverse effects and losses. Obviously, a contestable market is an ideal market, which is different from the reality. But it does not mean that contestable market theory is not suitable for our e-commerce industry. We need to study, how can the government lower the threshold of market entry, how to reduce exit sunk costs and create a fair environment for enterprises.

\section{The Theory of Contestable Markets does not Negate Government Regulation}

The importance of contestable markets theory lies in its exploration of a valuable framework. It produces some new concepts and analytical tools; it takes the external factors that decide the market structure into account; it highlights the importance of the sunk cost; it emphasizes the positive role of potential competition in promoting industrial efficiency.

The electronic commerce industry is relatively close to the contestable markets. Though Tmall takes monopoly position, its market share decreases while the shares of Jingdong and Vipshop increase. The emerging B2C business platform focuses on a particular sector of the industry, and has competitive advantages compared with Tmall and Jingdong. It can distribute to the business volume, and attract customers from these two platforms through price advantage and meeting customers' specific needs. Another point is that, professional vertical platform can quickly build exclusive electronic commerce platform by leasing cloud services, and access to Tmall and Jingdong. It can quickly cover a wide range of customers; the sunk cost is relatively low.

On the basis of this theory, the paper discusses how the government can control and regulate the e-commerce industry and B2C platforms.

\section{Control Policy Should Aim at Promoting the Contestability of B2C Market}

The theory of contestable market holds that the completely competitive market is only the ideal situation of the real world. The conclusions obtained from the completely competitive market should be applied to the reality with conditions. Using the competitive theory to analyze whether the government should enter the B2C e-commerce industry, following questions should be considered. First, from the perspective of government regulation, is there any protection against entry barriers of the $\mathrm{B} 2 \mathrm{C}$ e-commerce industry? At this stage, there is no restriction on the establishment of 
e-commerce enterprises. Therefore, the competitive condition of B2C market is objective. We can use standard methods of the competitive theory to analyze the potential competition pressure on e-commerce enterprises. It can be seen that, the theory of contestable markets does not provide us with the reason of cancelling government regulation, but provides the new standards to evaluate the policies which regulate the actual economic behaviors.

A logical reasoning of government's regulation in B2C e-commerce industry is that, we should try to eliminate factors which impede the competition in e-commerce market, and let the invisible hand to play its role, in order to get a result that is close to the result of completely competitive market. Therefore, according to several competitive conditions, policies can promote the competitiveness of the market from following aspects.

\subsection{Creating competitive environment and eliminating the adverse effects of sunk cost}

From the e-commerce platforms, payment is a very important link. The convenience and reliability of payment can affect users' perception. Alipay of Tmall and Tenpay of Tencent have natural monopoly characteristics. According to Analysys, in the first quarter of 2017, Alipay occupied $53.70 \%$ shares of the third party mobile payment market; Tenpay occupied $39.41 \%$. To access the third party payment platform, the cost of e-commerce enterprises is obviously higher than that of the enterprises which already have payment platforms.

The key of government regulation is to create a competitive environment for natural monopoly business. The central bank began to control third party access in 2017. 45 institutions lead by the Clearing Center of the Central Bank signed the Agreement on the Establishment of Network Clearing Limited Company in July 28, 2017. The establishment of "NetsUnion" is a very important act in government's regulation of the e-commerce industry. The central bank issued a document and clearly stipulated that the online payment business of non bank payment institutions should be transferred to "NetsUnion" platform; after June 30, 2018, all online payment service should be provided through the network platform. The purpose is to reduce the entry cost and lower the threshold for small and medium-sized enterprises to access the third party payment.

\subsection{Strengthening relevant legal construction to make the entry and exit of market more easily}

Competitive analysis shows that, restrictions on entry or exit will impede the competitiveness and ultimately damage economic efficiency. Traditional control policies do not only restrict the entry, but also refuse deficit enterprises to exit the market. On one hand, the monopoly in e-commerce industry is intensifying. On the other hand, the government is actively promoting the development of e-commerce industrial parks. The situation requires the government to actively guide the entry and exit of e-commerce enterprises when formulate industrial policies, and remove barriers to create a good competitive environment.

The government should provide public construction such as network platform, trading platform and payment platform for enterprises of vertical subdivision, lead them to the direction where the sunk cost is almost zero, and provide them with a good development space. The harmony and coexistence between these enterprises and incumbents like Jingdong and Tmall should be achieved to prevent Tmall and Jingdong from charging higher fees and setting monopoly price to obtain monopoly profits. The economies of scale and the introduction of competition should be avoided.

\subsection{The regulation of Tmall, Jingdong and entrants should follow the principle of non-equivalence}

If the access is completely free, the statuses of potential entrants and incumbent e-commerce enterprises are not equal, since companies like Tmall and Jingdong have the "first-mover advantages". The inequality will seriously damage the potential competition, so it should be offset by unequal control of incumbents and entrants. Incumbents' price response for entry should be inhibited, namely make $\mathrm{T}>0$. Because the price response will prevent entry behaviors, and lead the entry to a state of "uncertainty". Regulations of the government can make the e-commerce industry which has been monopolized to become a competitive industry, and help more e-commerce enterprises to take shape and develop healthily. 


\section{Policy about E-commerce Industry Based on Contestability Theory}

E-commerce Industrial Park is the platform, incubator and gathering area of e-commerce companies. When building e-commerce industrial parks, the government can create e-commerce investment environment from the concept of reducing sunk cost. (1) The government should create the hard environment for e-commerce investment, namely strengthening the construction of network infrastructure, payment platform, distribution terminals, intelligent logistics platforms, warehouses and other facilities. (2) The government should create the soft environment for e-commerce investment, namely to innovate the investment policy system, to improve the efficiency of business investment projects and to improve the investment promotion services. (3) The government should cultivate the e-commerce industrial chain. We should vigorously launch e-business chain projects based on supporting services like technology, logistics, payment, certification and data. Upstream and downstream industrial chains should also be introduced to form the agglomeration effect of e-commerce.

Supporting policies on the development of e-commerce industry should be implemented by stage.

First, e-commerce companies on trade logistics should be developed. We can develop B2B, C2C, B2C e-commerce platforms, develop e-commerce projects to provide e-commerce services to small and medium-sized enterprises, and build cross-border e-commerce platforms.

Second, the industrial platform for e-commerce companies should be developed. It is the task of implementing "Internet plus" and "two integrations" strategies and promoting the industry to develop towards the mid-to-high end. We should vigorously develop integrated service platform which includes information flow, business flow, logistics and capital flow, and vigorously promote the development of industrial platform for e-commerce companies.

Third, the construction of the e-business Industrial Park should be promoted. The e-commerce industry park (ECP) is the platform, carrier, incubator and agglomeration area of e-commerce enterprises. All localities should integrate a batch of buildings, standard workshops, warehouses and dwellings to build e-commerce industrial parks. E-commerce industrial parks can be built to concentrate e-commerce enterprises and support the construction of logistics services, in order to achieve online and offline development and solve the "last kilometer" problem.

Fourth, e-commerce should be developed in rural areas. At present, main problems facing the development of rural e-commerce include: the industrial agglomeration degree of agricultural products is not high; the lack of e-commerce personnel; the financing channels are not smooth; the lack of professional public services; the incomplete ecosystem; the lack of innovative and incentive mechanisms. Therefore, when developing rural e-commerce, the government should build 3 nets. The first is a sky net. The development of electronic commerce in rural areas cannot be realized without proper environment and atmosphere; the government needs to support the environment construction. The second is a ground net. We should pay more attention to the construction of logistics infrastructure, and get through the "last kilometer". The last is the human network. The introduction and return of talents are the key of rural e-commerce development.

\section{References}

[1] D.S. Su, Industrial Economics, Higher Education Press, Beijing, 2001.

[2] The Twenty-eighth Statistical Report on the Development of Internet in China

[3] L. Shen, Comparative analysis of the behaviors of Chinese and foreign card issuers based on bilateral market of credit card, J. China Economist. (11) 2008.

[4] Q.H. Zhang, G.L. Liu, Adjustment in the organizational form of telecommunications industry on the basis of contestability theory, J. Commercial Times. 2010

[5] H.B. Hu, Analysis on the cost of e-commerce under the condition of network economy, J. Journal of East China Normal University. 12 (2005).

[6] X.F. Liu, Analysis on costs and benefits of e-commerce carried out by enterprises, J. Journal of Harbin University of Commerce (Social Science Edition). 4 (2005). 